\title{
Lactoferrin addition to Tris-extender reduces the detrimental effects of cryopreservation on Egyptian buffalo semen
}

\author{
${ }^{1}$ Hussein Y.S., ${ }^{2}$ Shaba M.I. and ${ }^{2}$ EI-Sheshtawy R.I. \\ ${ }^{I}$ Department of Biotechnology, Animal Production Research Institute, Agricultural Research Centre, \\ Dokki, Giza, Egypt. \\ ${ }^{2}$ Department of Animal Reproduction and Artificial Insemination, National Research Centre, 33 \\ Buhouth St., Dokki, Giza, Egypt.
}

Received: 20 Oct. 2019/ Accepted 30 Nov. 2019/ Publication date: 10 Dec. 2019

\begin{abstract}
The freeze-thaw process results in structural and functional damages caused by over accumulation of reactive oxygen species (ROS). Addition of exogenous antioxidants to semen extender is of a great importance to overcome the oxidative damage during the freezing protocol. Objective: To evaluate the effect of tris-extender supplemented with a different concentrations of Lactoferrin on buffalo bull semen preservability. Methods: Different concentrations of lactoferrin $(2 \mathrm{mg} / \mathrm{ml}, 4 \mathrm{mg} / \mathrm{ml}$ and $6 \mathrm{mg} / \mathrm{ml})$ were added to tubes containing Tris-citrate egg yolk extender with $20 \%(\mathrm{v} / \mathrm{v})$ egg yolk and 7\% (v/v) glycerol. The control tubes were Tris containing (0 lactoferrin). The extended semen was subjected to semen freezing protocol. Semen assessment including motility, viability \%, abnormality\%, intact of sperm membrane (hypo-osmotic swelling test) and acrosome status were carried out for both cooled and frozen semen. Results: The post cooling results revealed non-significant improvement in sperm membrane integrity (HOST) of all used lactoferrin concentrations, especially for TL1 $(72.46 \pm 0.46)$ compared to control $(56.61 \pm 8.93)$. Other sperm parameters were kept as the control. After thawing, sperm motility exhibited improvement $(P<0.009)$ for all concentrations of the used lactoferrin addition $(58.33 \pm 1.66,51.66 \pm 1.66$ and $53.33 \pm 3.33$ respectively) as compared to the control $(43.33 \pm 1.66)$. Sperm viability percent was improved $(P<0.002)$ in TL1 $(86.66 \pm 1.66)$ when compared to the control $(80.66 \pm 0.66)$. Moreover, a significant reduction $(P<0.004)$ in sperm abnormalities were observed in TL1 $(8.66 \pm 0.33)$ and TL3 $(8.33 \pm 0.33)$ when compared to the control $(10.33 \pm 0.33$ ). Sperm membrane integrity (HOST, 57.48 \pm 11.68 , $58.37 \pm 3.72$ and $69.51 \pm 3.91)$ was kept as the control $(57.90 \pm 0.27)$ and acrosome intact percent $(89.33 \pm 1.15,88.66 \pm 3.21$ and $89.66 \pm 4.50)$ was maintained as control $(87.50 \pm 5.00)$. Conclusions: The concentration of lactoferrin (TL1, $2 \mathrm{mg} / \mathrm{ml}$ extender) exhibited the best sperm quality in post-thawed semen process.
\end{abstract}

Keywords: Lactoferrin, Tris-extender, buffalo bull and Semen cryopreservation.

\section{Introduction}

The low rate of success of semen cryopreservation and poor rate of in vitro fertilization (IVF) may be referred to temperature reduction, cellular dehydration, freezing and thawing which associated with increased premature capacitation of spermatozoa. These alterations may not affect motility but reduces lifespan, ability to interact with the female reproductive tract and sperm fertility (Gadea et al., 2004). In bovine semen, reactive oxygen species (ROS) are generated primarily by dead spermatozoa via an aromatic amino acid oxidase catalyzed reaction (Medeiros et al., 2002). The low concentrations of ROS are physiologically involved in the maintenance of the fertilizing ability and capacitation (acrosome reaction) of spermatozoa, but excessive ROS impairs sperm function and enzymatic activity (O'Flaherty and Matsushita-Fournier, 2017). Freezing and thawing processes also lead to the generation of ROS. Cryopreservation of bovine semen often exert a hazardous source for the oxidative attack on sperm due to decreased activities of antioxidant enzymes and the sperm membrane become more susceptible to oxidative damage (El-Sisy et al., 2007) which affect the membrane integrity (Awda et al., 2009). Sperm cells contain high concentrations of polyunsaturated fatty acids, which are highly susceptible to lipid peroxidation (LPO) with subsequent impairment of motility,

Corresponding Author: Hussein Y.S., Department of Biotechnology, Animal Production Research Institute, Agricultural Research Centre, Dokki, Giza, Egypt.

E-Mail: yshussein@hotmail.com 
membrane integrity, fertilizing capacity and metabolic alterations of spermatozoa biology (Cassani et al., 2005).

Buffalo spermatozoa must be extended using a suitable cryoprotective medium to be used later in artificial insemination programs. Tris-based extenders are frequently used for semen cryopreservation in domestic animals (Purdy, 2006 and El-Seadawy et al., 2017). ROS is represented by the hydrogen peroxide $\left(\mathrm{H}_{2} \mathrm{O}_{2}\right)$ and the superoxide anion $\left(\mathrm{O}_{2-}\right)$ are produced as a result of spermatozoal oxidative stress (Ball, 2008). Seminal plasma contain detrimental amount of antioxidants which eliminate ROS that decrease cellular damage (Meyers, 2012). The over accumulation of ROS cause lipid peroxidation with subsequent membrane and DNA damage leads to decrease both motility and viability (Baumber et al., 2003). The antioxidant system in the cell including, catalase (CAT), reduced glutathione (GSH), glutathione peroxidase (GSH-PX), superoxide dismutase (SOD), and metal chelators (Lactoferrin, transferrin, and ceruloplasmin) has been identified as a defense functioning mechanisms against LPO in semen (O'Flaherty, 2014). It is also an important system in maintaining viability and sperm motility (Bilodeau et al., 2001 and Agarwal et al., 2007). This antioxidant capacity in the sperm cell may however be insufficient to prevent LPO during the freeze-thawing process. Addition of antioxidants proteins found in seminal plasma, such as lactoferrin (Lf) and catalase (Cat), to the freezing semen extenders could protect the sperm during cryopreservation (Martins et al., 2014). Lactoferrin is an iron-binding protein found in many exocrine fluids, blood plasma and neutrophils (Mahdi and Houbi, 2016); which was previously tested as an antioxidant added to extender of equine semen (Martins et al., 2016). So, the objective of the current study was to evaluate the effect of tris-extender supplemented with different concentrations of Lactoferrin on buffalo bull semen parameters.

\section{Materials and Methods}

\section{Preparation of lactoferrin tris extender:}

Three different concentrations of bovine milk lactoferrin (Sigma-Aldrich, L9507), 2mg/ml $\left(\mathrm{TL}_{1}\right), 4 \mathrm{mg} / \mathrm{ml}\left(\mathrm{TL}_{2}\right)$ and $6 \mathrm{mg} / \mathrm{ml}\left(\mathrm{TL}_{3}\right)$ were added into tubes containing Tris-citrate egg yolk extender with $20 \%(\mathrm{v} / \mathrm{v})$ egg yolk and $7 \%(\mathrm{v} / \mathrm{v})$ glycerol. The control tubes were Tris containing zero $\mathrm{mg} / \mathrm{ml}$ lactoferrin.

\section{Semen collection and initial evaluation:}

Five mature Egyptian buffalo-bulls with superior quality semen characteristics maintained at the International Livestock Management Training Center (ILMTC), belonging to Animal Production Research Institute; Agricultural Research Centre; Dokki, Giza; Egypt, during spring were used for this study as semen source. Semen ejaculates were collected from bulls using an artificial vagina at weekly intervals for 5 concessive weeks. The semen samples were initially evaluated for volume (in graduated tube), concentration using Thoma ruling of the neubauer haemocytometer and morphological appearance were evaluated according to Boe-Hansen et al. (2018).

The collected semen samples with more than $70 \%$ motility and $80 \%$ morphologically normal spermatozoa were admitted to freezing procedure. The ejaculates were pooled in order to have sufficient semen for a replicate and to eliminate the bull effect. The semen was given a holding time for 10 minutes at $37^{\circ} \mathrm{C}$ in a water bath before dilution to be evaluated.

\section{Semen processing:}

Semen samples were extended in the Tris-extender containing lactoferrin with dilution rate 1:5 to ensure 60 million motile spermatozoa $\mathrm{mL}^{-1}$., then cooled up to $5^{\circ} \mathrm{C}$, equilibrated for $4 \mathrm{~h}$ including the cooling time in and evaluated for post cooling sperm motility, viability, total abnormalities and acrosome and membrane integrities before processing.

Semen was packed into $0.25 \mathrm{~mL}$ polyvinyl French straws (IMV, France). After equilibration period, the straws were placed horizontally and frozen in $4 \mathrm{~cm}$ above liquid nitrogen $\left(\mathrm{LN}_{2}\right)$ vapor for 10 minutes and were then dipped stored in liquid nitrogen at $-196^{\circ} \mathrm{C}$. 


\section{Assessment of semen quality parameters:}

Frozen straws were thawed individually at $37{ }^{\circ} \mathrm{C}$ for $60 \mathrm{~s}$ in a water bath for microscopic evaluation (Roof et al., 2012). The parameters studied were sperm motility, sperm viability, sperm abnormality, sperm membrane integrity (HOST; Hypo-osmotic swelling test) and percent of normal intact acrosome in cooled and frozen- thawed semen.

\section{Sperm motility:}

Subjective motility was observed using phase contrast microscope (Olympus Optical Co. Ltd., Japan). Visual motility was assessed microscopically with closed circuit television (de Paz et al., 2010).

Live and abnormal spermatozoa (\%):

Viability and morphological abnormalities, of at least 200 spermatozoa, were done using Eosin $(0.5 \%)$-Nigrosin $(0.1 \%)$ staining mixture; dead cells were stained by the Eosin as described by Barbas and Mascarenhas (2009).

\section{Sperm membrane integrity:}

Hypoosmotic Swelling Test (HOST) in $100 \mathrm{mOsm} / \mathrm{L}$ was held to evaluate the functional intact sperm plasma membrane (membrane permeability), based on swollen tails; 200 hundred spermatozoa were counted and the percentage of spermatozoa with curled tails (swollen/intact plasma membrane) was calculated according to Hufana-Duran et al. (2015).

\section{Intact normal acrosome percent:}

The acrosomal membrane intact was evaluated by immerging of $30 \mu 1$ air dried of thawed semen into previously prepared Giemsa's stain solution and kept at $37^{\circ} \mathrm{C}$ for $2 \mathrm{hrs}$ as described by Chowdhury et al. (2014). The present of intact acrosome was recorded for 200 spermatozoa that were randomly examined using phase contract microscope.

\section{Statistical analysis:}

Output data were analyzed by one-way analysis of variance (ANOVA), followed by Duncan (Duncan, 1955) test to determine significant differences in all the parameters among all groups, with SPSS Version 14.0 for Windows (SPSS, 2005). Data were tabulated as Mean \pm SD. Differences with values of $\mathrm{P}<0.05$ were considered to be statistically significant.

\section{Results}

\section{Sperm assessment after cooling:}

The post cooling results (Table 1) revealed improvement in sperm membrane integrity (HOST) in all the concentrations of the used lactoferrin which was non-significant $(\mathrm{P}<0.149)$ in TL1 (72.46 \pm 0.81$)$ when compared to the control $(56.61 \pm 15.49)$. All the other sperm parameters were nearly similar as the control.

Table 1: Effect of Tris extender enriched with Lactoferrin on the cooled extended buffalo bull semen (Mean $\pm \mathrm{SD}$ ).

\begin{tabular}{lccccc}
\hline \multicolumn{1}{c}{ Diluent } & Motility & Viability & Abnormalities & HOST & Acrosome \\
\hline Control & $90.00 \pm 0.00$ & $88.33 \pm 2.88$ & $6.66 \pm 0.57$ & $56.61 \pm 15.49$ & $83.33 \pm 5.77$ \\
TL1 & $91.66 \pm 2.88$ & $92.00 \pm 3.46$ & $7.66 \pm 0.57$ & $72.46 \pm 0.81$ & $90.66 \pm 1.15$ \\
TL2 & $91.66 \pm 2.88$ & $92.33 \pm 4.04$ & $6.66 \pm 0.57$ & $69.26 \pm 0.46$ & $86.33 \pm 2.31$ \\
TL3 & $91.66 \pm 2.88$ & $91.66 \pm 2.88$ & $6.66 \pm 0.57$ & $65.13 \pm 0.23$ & $84.33 \pm 4.04$ \\
$\boldsymbol{P}$-value & NS & NS & NS & NS & NS \\
\hline
\end{tabular}

* Means within each column followed by different letters differ at $P<0.01$. Control=Tris-citrate egg yolk extender, TL1 $=$ Tris $+2 \mathrm{mg} / \mathrm{ml}$ Lactoferrin, TL2 $=$ Tris $+4 \mathrm{mg} / \mathrm{ml}$ Lactoferrin and TL3 $=$ Tris $+6 \mathrm{mg} / \mathrm{ml}$ Lactoferrin, HOST=Hypoosmotic Swelling Test, NS=non-significant. 


\section{Post-thawing sperm assessment:}

The post-thawing results (Table 2) exhibited significant improvement $(P<0.009)$ of sperm motility in all concentrations of lactoferrin $(58.33 \pm 2.88,51.66 \pm 2.88$ and $53.33 \pm 5.77$, respectively) as compared to the control $(43.33 \pm 2.88)$. Similarly, sperm viability percent was increased $(P<0.002)$ in TL1 (86.66 \pm 2.88$)$ compared to the control $(80.66 \pm 1.15)$. However a significant reduction $(P<0.004)$ in sperm abnormalities in TL1 $(8.66 \pm 0.57)$ and TL3 $(8.33 \pm 0.57)$ compared to the control $(10.33 \pm 0.57)$ while; sperm membrane integrity (HOST) and acrosome percent were maintained as control tubes.

Table 2. Effect of Tris extender enriched with Lactoferrin on the post- thawed extended buffalo bull Semen $($ Mean $\pm \mathrm{SD})$.

\begin{tabular}{cccccc}
\hline Diluent & Motility & Viability & Abnormalities & HOST & Acrosome \\
\hline Control & $43.33 \pm 2.88^{\mathrm{a}}$ & $80.66 \pm 1.15^{\mathrm{b}}$ & $10.33 \pm 0.57^{\mathrm{b}}$ & $57.90 \pm 0.27$ & $87.50 \pm 5.00$ \\
TL1 & $58.33 \pm 2.88^{\mathrm{b}}$ & $86.66 \pm 2.88^{\mathrm{c}}$ & $8.66 \pm 0.57^{\mathrm{a}}$ & $57.48 \pm 11.68$ & $89.33 \pm 1.15$ \\
TL2 & $51.66 \pm 2.88^{\mathrm{b}}$ & $76.33 \pm 2.31^{\mathrm{a}}$ & $10.33 \pm 0.57^{\mathrm{b}}$ & $58.37 \pm 3.72$ & $88.66 \pm 3.21$ \\
TL3 & $53.33 \pm 5.77^{\mathrm{b}}$ & $80.66 \pm 1.15^{\mathrm{b}}$ & $8.33 \pm 0.57^{\mathrm{a}}$ & $69.51 \pm 3.91$ & $89.66 \pm 4.50$ \\
$\boldsymbol{P}$-value & 0.009 & 0.002 & 0.004 & NS & NS \\
\hline
\end{tabular}

*Means within each column followed by different letters differ at $P<0.01$. Control=Tris-citrate egg yolk extender, TL1 $=$ Tris $+2 \mathrm{mg} / \mathrm{ml}$ Lactoferrin, TL2 $=$ Tris $+4 \mathrm{mg} / \mathrm{ml}$ Lactoferrin and TL3 $=$ Tris $+6 \mathrm{mg} / \mathrm{ml}$ Lactoferrin, HOST=Hypoosmotic Swelling Test, NS=non-significant.

\section{Discussion}

Several factors have been reported to influence the cryosurvival of spermatozoa including osmotic stress, ice crystal formation, cryoprotectants toxicity and the variability of individuals (Neild et al., 2003 and Ferrusola et al., 2009). Among various causes, oxidative stress has been reported to affect the fertility and physiology of frozen/thawed spermatozoa (Agarwal et al., 2008). Oxidative stress occurs as a consequence of imbalance between the levels of reactive oxygen species (ROS) production and the antioxidant capacity of the cell (Smith et al., 2006 and Halliwell, 2006). Excessive amounts of ROS are harmful to the sperm cells, low level of these molecules are required to induce sperm capacitation in human, a process that is required for the spermatozoa to acquire their fertilizing ability. Under oxidative stress, spermatozoa suffer extensive damage such as peroxidation of membrane lipids, DNA fragmentation, low mitochondrial membrane activity (Halliwell and Gutteridge 2007 and Koppers et al., 2008) and inactivation of enzymes associated with motility (Cassani et al., 2005). Lipid peroxidation causes loss of integrity and fluidity of the sperm membrane necessary for membrane fusion during fertilization, there over to DNA and chromatin damage of spermatozoa (Gallon et al., 2006).

Our results revealed improvement of sperm parameters after cooling. Post-thawing findings revealed improvement in sperm motility, livability and reduction in sperm abnormalities with the low used concentrations of lactoferrin addition. The current results are in agreement with those reported by Martins et al. (2016) in equine sperm membrane and acrosome integrity which were improved by lactoferrin addition to the freezing extender. The improved semen quality post cooling and post freezing may be due to the high affinity of lactoferrin to iron sequestration from the external environment and prevent it from performing its catalytic Haber-Weiss reaction (O'Flaherty, 2014), thus diminishing $\mathrm{O}_{2}$ and $\mathrm{H}_{2} \mathrm{O}_{2}$ production and consequently decreased Lipid peroxidation (Baker, 2005).

Lactoferrin acts as a sperm-coating antigen which may play an important role on the oxidative metabolism motility (Martins et al., 2014); working as a protecting agent to the spermatozoa, increases the percentage of sperm with functional membrane and decreased the lipid oxidant mediators (Martins et al., 2018). A dose-dependent increase in both induced acrosome reaction and tyrosine phosphorylation of sperm proteins were observed in the presence of Lactoferrin (Zumoffen et al., 2015). That was confirmed when low concentrations of Lactoferrin were added to in vitro fertilization medium of buffalo oocytes which significantly enhanced the rates of fertilization in vitro (Hussein and Badr 2017). 
In conclusion, based on current results, the addition of lactoferrin to enhances the post-thawing motility and viability, with low abnormality rate of cryopreserved buffalo bull spermatozoa in a dosedependent manner. The concentration of $2 \mathrm{mg}$ lactoferrin per one ml. Tris-extender exhibited the best sperm quality in post-thawed semen process.

\section{References}

Agarwal, A., K. Makker and R. Sharma, 2008. Clinical relevance of oxidative stress in male factor infertility: An Update. Am. J. Reprod. Immunol., 59: 2-11.

Agarwal, A., S.A. Prabakaran and S.C. Sikka, 2007. Clinical relevance of oxidative stress in patients with male factor infertility: evidence-based analysis. American Urological Association, Education and Researching. Linthicum, MD, AUA; 26:1-12.

Awda, B.J., M. Mackenzie-Bell and M.M. Buhr, 2009. Reactive oxygen species and boar sperm function. Biol. Reprod., 81:553-561.

Baker, H.M., 2005. Molecular structure, binding properties and dynamics of lactoferrin. Cell. Mol. Life Sci.; 62:2539.

Ball, B.A., 2008. Oxidative stress, osmotic stress and apoptosis: impacts on sperm function and preservation in the horse. Anim. Reprod. Sci.,107:257-267.

Barbas, J.P. and R.D. Mascarenhas, 2009. Cryopreservation of Domestic Animal Sperm Cells. Cell and Tissue Banking, 10, 49-62.

Baumber, J., B.J. Ball and S. Meyers, 2003. Reactive Oxygen Species and Cryopreservation Promote DNA Fragmentation in Equine Spermatozoa. J. Androl., 24:621-628.

Bilodeau, J.F., S. Blanchette, I.C. Gagnon and M.A. Sirard, 2001. Thiols prevent H2O2-mediated loss of sperm motility in cryopreserved bull semen. Theriogenology, 56: 275-286.

Boe-Hansen, G.B., M.R.S. Fortes and N. Satake., 2018. Morphological defects, sperm DNA integrity, and protamination of bovine spermatozoa. Andrology, 6, 627-633.

Cassani, P., M.T. Beconi and C. O'Flaherty, 2005. Relationship between total superoxide dismutase activity with lipid peroxidation, dynamics and morphological parameters in canine semen. Anim. Reprod. Sci., 86:163-173.

Chowdhury, S., S. Das, T. Gupta, D. Sana and S. Bose, 2014. Evaluation of frozen semen by acrosomal integrity and sperm concentration - two vital quality parameters of male fertility in bovines Explor Anim Med Res, 4(1), p 101-107

de Paz, P., M.C. Esteso, M. Alvarez, M. Mata, C.A. Chamorro and L. Anel, 2010. Development of extender based on soybean lecithin for its application in liquid ram semen. Theriogenology, 74: 663-671.

Duncan, D.B., 1955. Multiple Range and Multiple F. Test Biometrics. Biometrics. 11: 1-42.

El-Seadawy, I. E., W.S. El-Nattat, M.M. El-Tohamy, S.A.H. Aziza, Y.A. El-Senosy and A.S. Hussein, 2017. Preservability of rabbit semen after chilled storage in tris based extender enriched with different concentrations of Propolis ethanolic extract (PEE). Asian Pac. J. Reprod.; 6: 68-76.

El-Sisy, G.A., W.S. El-Nattat and R.I. El-Sheshtawy, 2007. Buffalo semen quality, antioxidants and peroxidation during chilling and cryopreservation. Online J. Vet. Res., 11: 55-61.

Ferrusola, C.O., F.L. Gonzalez, G.B. Macias, C. Salazar-Sandoval and R.A. Morillo, 2009. Effect of cryopreservation on nitric oxide production by stallion spermatozoa. Biol. Reprod., 81: 1106-1111.

Gadea, J., E. Selles, M.A. Marco, P. Coy, C. Matas, R. Romar and S. Ruiz, 2004. Decrease in glutathione content in boar sperm after cryopreservation. Effect of the addition of reduced glutathione to the freezing and thawing extenders. Theriogenology, 62: 690-701.

Gallon, F., C. Marchetti, N. Jouy and P. Marchetti, 2006. The functionality of mitochondria differentiates human spermatozoa with high and low fertilizing capability. Fert. Steril., 86: 15261530 .

Halliwell, B. and J. Gutteridge, 2007. Free radicals in biology and medicine, Oxford University; Press, New York.

Halliwell, B., 2006. Oxidative stress and neurodegeneration: where are we now? J. Neurochem., 97: 1634-1658. 
Hufana-Duran, D., R. P. Mallari, D. P. Suba, P. G. Duran, E. A. Abella, and F.V. Mamuad, 2015. Hypo-Osmotic Swelling Test for Membrane Integrity Evaluation of Frozen-Thawed Water Buffalo (Bubalus bubalis Linn.) Spermatozoa. Philippine Journal of Science, 144 (2): 209-219.

Hussein, Y.S. and M.R. Badr, 2017. Concentration dependent of Lactoferrin can improve in vitro maturation, fertilization and embryonic development of Buffalo oocytes. J. Anim. Pol. Prod., Mansoura Univ., 8 (12): 491- 494.

Koppers, A.J., G.N. De Iuliis, J.M. Finnie, E.A. McLaughlin and R.J. Aitken, 2008. Significance of mitochondrial reactive oxygen species in the generation of oxidative stress in spermatozoa. J. Clin. Endocrinol. Metabol., 93: 3199-3207.

Mahdi, Z.A. and A. A. Houbi, 2016. Effect of lactoferrin addition to semen of Awassi rams on the bacterial contamination. The Iraqi Journal of Agricultural Sciences, 47(6):1461-1467.

Martins, H.S., G.C. da Silva, S.F. Cortes, F.O. Paes, O.A. Martins Filho, M. Araujo, R. Stahlberg and M.A. Lagares, 2018. Lactoferrin increases sperm membrane functionality of frozen equine semen. Reprod Domest Anim., 53(3):617-623.

Martins, H.S., M.R. Souza, C.F.A.M. Penna, G.C. da Silva, S.F. Côrtes, R. Stahlberg and M.A. Lagares, 2016. Milk, caseinate and lactoferrin addition to equine semen cooling extenders. Andrologia, 48: 950-956.

Martins, H.S., M.F. Brito, I.B.M. Sampaio, R. Stahlberg, M.R. Souza, C.F.A.M. Penna and M.A. Lagares, 2014. Effects of antioxidants lactoferrin and catalase on stallion frozen semen. Reprod. Fert. Dev., 27: 126-127.

Medeiros, C.M., F. Forell, A.T. Oliveira and J.L. Rodrigues, 2002. Current status of sperm cryopreservation: Why isn't better. Theriogenology, 57: 327-344.

Meyers, S.A., 2012. Cryostorage and oxidative stress in mammalian spermatozoa. In Studies on Men's Health and Fertility- Part of the series Oxidative Stress in Applied Basic Research and Clinical Practice, A. Agarwal, R.J. Aitken, J.G. Alvarez (eds.). Melbourne, Australia: Springer Nature, pp. 41-56.

Neild, D.M., B.M. Gadella, M.G. Chaves, M.H. Miragaya, B. Colenbrander and A. Aguero, 2003. Membrane changes during different stages of a freeze-thaw protocol for equine semen cryopreservation. Theriogenology, 59: 1693-1705.

O'Flaherty C. and D Matsushita-Fournier, 2017. Reactive oxygen species and protein modifications in spermatozoa. Biology of Reproduction, 97(4), 577-585.

O'Flaherty, C., 2014. The Enzymatic Antioxidant System of Human Spermatozoa. Advances in Andrology Vol. 2014, Article ID 626374, 1-15.

Purdy, P.H., 2006. A review on goat sperm cryopreservation. Small Rumin. Res.; 63:215-225.

Roof. D.J., S. Bowley, L.L. Price and D.J. Matsas, 2012. Comparison of two commercial extenders for cryopreservation of goat semen without sperm washing. Theriogenology, 77: 412-420.

Smith, R., H. Kaune, D. Parodi, M. Madariaga, R. Rios, I. Morales and A. Castro, 2006. Increased sperm DNA damage in patients with varicocele: relationship with seminal oxidative stress. Hum. Reprod., 21: 986-993.

SPSS. SPSS v .14.0 for Windows Evaluation Version Release. 14.0.0, 2005.

Zumoffen, C.M., E. Massa, A.M. Caille, M.J. Munuce and S.A. Ghersevich, 2015. Effects of lactoferrin, a protein present in the female reproductive tract, on parameters of human sperm capacitation and gamete interaction Andrology, 3, 1068-1075. 